\title{
Inflammation, infection and depression: an evolutionary perspective
}

\author{
Caroline Doyle ${ }^{1 *}$ (D), Walker A. Swain ${ }^{2}$, Holly A. Swain Ewald ${ }^{3}$ and Paul W. Ewald ${ }^{3}$ \\ ${ }^{1}$ Department of Biology, Bellarmine University, Louisville, KY 40205, USA, ${ }^{2}$ Department of Lifelong Education, \\ Administration, and Policy, University of Georgia, Athens, GA 30602, USA and ${ }^{3}$ Department of Biological Sciences, \\ University of Louisville, Louisville, KY 40292, USA \\ ${ }^{\star}$ Corresponding author. E-mail: cdoyle@bellarmine.edu
}

\begin{abstract}
The evolutionary basis for clinical depression is not well understood. A growing body of literature that is not based on evolutionary logic links inflammation to depression. Integration of these findings with an evolutionary framework for depression, however, needs to address the reasons why the body's inflammatory response would be regulated so poorly that it would result in incapacitating depression. Pathogen induction of inflammation offers an explanation, but the extent to which the association between inflammation and depression can be attributed to general inflammation as opposed to particular effects of proinflammatory pathogens remains unclear. This paper reports a study of sexually transmitted pathogens, which addresses this issue. Although several sexually transmitted pathogens were associated with depression according to bivariate tests, only Chlamydia trachomatis and Trichomonas vaginalis were significantly associated with depression by a multivariate analysis that accounted for correlations among the pathogens. This finding is consistent with the hypothesis that infection may contribute to depression through induction of tryptophan restriction, and a consequent depletion of serotonin. It reinforces the idea that some depression may be caused by specific pathogens in specific evolutionary arms races with their human host.
\end{abstract}

Keywords: Inflammation; depression; sexually transmitted infection; Chlamydia trachomatis; tryptophan

Media summary: Infection-associated depression correlates with Chlamydia trachomatis more strongly than general inflammatory responses.

\section{Introduction}

The evolutionary reasons for the widespread presence of clinical depression are unclear. One line of evolutionary reasoning suggests that depression may cause individuals to shift away from unattainable goals (Nesse 2019). This explanation, however, seems inadequate for prolonged, incapacitating depression which should be purged by natural selection (Coyne 2010; Nesse 2019). The adaptive argument for short-term depression, however, may help explain the presence of adaptive neurological circuitry which then could function counter-productively when depression is prolonged and intractable. One hypothesis within this category of explanations invokes mismatches between modern and ancestral environments. Modern environments may have situational traps, such as economic immobility, which could keep depressed individuals from changing their living circumstances and thereby rebound from low mood (Nesse 2019). An alternative mismatch hypothesis proposes that the neocortex is particularly vulnerable to damaging environmental agents and that clinical depression results from the elevated presence of such hazards in modern relative to ancestral environments (Galecki and Talarowska 2017).

(c) The Author(s) 2019. This is an Open Access article, distributed under the terms of the Creative Commons Attribution licence (http://crea tivecommons.org/licenses/by/4.0/), which permits unrestricted re-use, distribution, and reproduction in any medium, provided the original work is properly cited. 
An alternative category of explanation invokes infection. Depression has been linked to innate immunological responses to infection and therefore could be interpreted as part of a mechanism that may facilitate recovery, for example, by encouraging rest, or may prevent additional infections in the depressed individual or kin (Anders et al., 2013; Kinney and Tanaka 2009; Nesse 2019; Raison and Miller 2013b). As is the case with adaptive explanations of short-term depression that rely on goal-shifting, these hypotheses of infection-induced depression do not account well for prolonged, incapacitating depression. It is presumed that the fitness costs of prolonged, incapacitating depression must be incurred in order to obtain the even greater protective benefits of depression.

Clinical depression is distinguished from temporarily suppressed mood largely on the basis of its persistence for at least two weeks (American Psychiatric Association 2013). Accordingly, low mood associated with acute infectious disease is generally considered to be a manifestation of the disease rather than clinical depression. Persistent infections, however, might contribute to prolonged and debilitating depression that has not yet been attributed to infection. Evolutionary considerations emphasize that manifestations of infectious disease could benefit the host, parasite or neither (Ewald 1980). The reasoning leading to this conclusion is based on the coevolutionary instability that is associated with the evolutionary conflicts of interest between parasite and host. In this context, persistent, debilitating depression is not presumed to be an adaptation of the host or the infectious agent. Rather, an adaptive basis for depression may be manifested with an increased intensity or persistence that is beneficial to neither host nor pathogen but results instead from a disruption of the normal regulation of depression, a side effect of the coevolutionary arms race between particular parasites and their hosts.

Recent research has focused on the possibility that inflammation may play a causal role. Depression has been correlated with levels of inflammatory proteins (Khandaker et al. 2014; Pasco et al. 2010a, 2010b) and autoimmunity (Benros et al. 2013), but anti-inflammatory treatment has ameliorated depression inconsistently across studies (Baune 2017; Cubala and Landowski 2014; Eyre et al. 2015; O. Kohler et al. 2014, 2016a) and among patients within studies that have different levels of inflammation (Raison et al. 2013).

Infections have been suggested as instigators of immunological responses that could lead to depression (Benros et al. 2013; Canli 2014; Doyle et al. 2015; Maes et al. 2009; Miller et al. 2009; Raison and Miller 2013b). Several pathogens that cause persistent infections have been associated with depression. Human papillomavirus (HPV) has been associated with depressive symptoms in human immunodeficiency virus (HIV)-infected patients (Dodd et al. 2009; Lopez et al. 2013). Chlamydia trachomatis has been associated with depression in women tested during their annual check-ups (Doyle et al. 2015). A meta-analysis (Wang et al. 2014) found significant associations of depression with several persistent pathogens but did not account for correlations among these pathogens.

Although associations between infection and depression are often interpreted as occurring through the intervening variable of inflammation (Benros et al. 2013; Miller et al. 2009; Raison and Miller 2013b), several findings emphasize the need to consider more specific effects of infectious agents. In a low- to middle-income population in Detroit, cytomegalovirus was correlated with depression, but inflammatory markers were not (Simanek et al. 2014). Similarly, cytomegalovirus was correlated with depression in elderly Latinos in northern California, but inflammatory markers and several other persistent pathogens (herpes simplex virus, varicella zoster virus, Helicobacter pylori and Toxoplasma gondii) were not (Simanek et al. 2018b). In a nationwide US study cytomegalovirus and $H$. pylori were associated with depression in women, but a marker of inflammation (C-reactive protein) was not (Simanek et al. 2018a). In the meta-analysis mentioned above (Wang et al. 2014), an association of CMV with depression fell just short of statistical significance, but this analysis did not include any of the more recent studies by Simanek and colleagues cited above.

The variation in the association of depression with both inflammation and infection is consistent with the looseness of the associations of depression with indicators of inflammation and the caveat that depression should not be categorized simply as an inflammatory disorder (Raison and Miller 2013a). Associations of depression with specific infectious agents are difficult to interpret because 
different infections may occur in the same patient, particularly if they are transmitted by the same route. Sexual transmission, in particular, may favor co-occurrence because sexually transmitted infections are often inapparent and nearly always persistent. The contribution of a sexually transmitted pathogen to depression may therefore be inconspicuous because of asymptomatic infection and ambiguous because it could co-occur with other sexually transmitted pathogens that do not contribute to depression.

Inflammatory responses are complex and variable. Joint consideration of infection and inflammation raises the possibility that some pathogens may affect aspects of immunological responses in ways that lead to depression, whereas others may not. It was hypothesized (Doyle et al. 2015) that the association of depression with $C$. trachomatis resulted from persistent restriction of tryptophan, which the body invokes in association with inflammation as an adaptation to defend against infection (Olive and Sassetti 2016; Schmidt and Schultze 2014). This restriction may be chronically stimulated by C. trachomatis because this bacterium synthesizes its own tryptophan (Aiyar et al. 2014) and thus may survive in the presence of tryptophan restriction. Tryptophan is the precursor of serotonin, which plays a role in modulating mood (Fakhoury 2016; S. Kohler et al. 2016b; Kupfer et al. 2012); restricted tryptophan levels may therefore result in chronically depleted serotonin and hence low mood (Akers and Tan 2006).

The study by Doyle et al. (2015), which correlated Chlamydia trachomatis with depression, did not find significant associations with the other sexually transmitted pathogens that were evaluated: Neisseria gonorrhoeae, Treponema pallidum, Candida albicans, Trichomonas vaginalis, HPV and HIV. The study, however, was based on only 500 women, and sample sizes for C. trachomatis were greater than for most of the other tested pathogens (Doyle et al. 2015). A larger study population is needed to determine whether sexually transmitted pathogens other than C. trachomatis are associated with depression. One particularly relevant uncertainty pertains to T. vaginalis; it was associated with a doubling of the risk of depression, but this numerical association was not statistically significant (Doyle et al. 2015). Resolution of these uncertainties bears on whether efforts to prevent infection-induced depression should focus on particular pathogens or inflammation in general.

To address this issue we conducted a study using data from the Kentucky Women's Health Registry at the University of Kentucky's Center for the Advancement of Women's Health, which includes health-related information from over 17,000 women. We focus on women to build on the previous study of women (Doyle et al. 2015) and because effects of infection on depression might be stronger in women than in men as a result of the reliance on tryptophan restriction as part of elevated innate immunity during the luteal phase of the menstrual cycle (Hrboticky 1989; Doyle 2015). At that time tryptophan restriction can occur in response to estrogen (through effects on dendritic cells and macrophages; Xiao et al. 2004) even though other aspects of immune function are suppressed.

\section{Methods}

Reproductive-aged women 18-40 years of age were selected as subjects from the Kentucky Women's Health Registry (currently 'Wellness, Health and You'). Participants were recruited from throughout Kentucky using brochures at the University of Kentucky health care clinics, state and county health departments, county agricultural extension offices, offices of private physicians, women's professional organizations, homemaker organizations and health-related events. Participants completed a registry questionnaire electronically or on paper after providing consent. All information was self-reported.

Although depression can be manifested by a variety of indicators, a duration of at least two weeks is a generally agreed upon threshold for distinguishing clinical depression from transient depression (https://www.psychiatry.org/patients-families/depression/what-is-depression). We therefore included in the depressed category anyone who responded that they had been 'down, depressed or hopeless' for a duration of at least two weeks at some point in their life (question U2a in Appendix 1). Participants were queried for pathogens and infectious conditions, socioeconomic and demographic status, drug use and lifestyle variables (Table 1). The timing of depression and infection was not 
noted in the directory. Our results therefore correlate depression with any of these variables without reference to the order of occurrence. Demographic details are presented in Table 2.

Immune suppression and state of infection often vary with the menstrual cycle (Doyle et al. 2007). Subjects were therefore excluded from the study if they reported menstrual disruption or cessation, were using hormonal birth control or hormone replacement therapy, were pregnant or postpartum, or had undergone an ovarectomy or hysterectomy (the last two were not distinguished in the registry).

For bivariate comparisons, chi-squared tests were performed. Boneferroni corrections were used to account for multiple comparisons. Although the correlations between the individual variables and reports of repression provide useful descriptive information, the possibility for correlations among the included pathogens, individual demographics and risk behavior indicator variables necessitate a multivariate analysis. For a multiple regression analysis we estimated the probability of an individual reporting depression of at least two weeks duration using a linear probability model (LPM) in which depression was considered as a function of participant characteristics and infection variables. In this analysis we used three separate models, focusing first on infection variables alone, then adding sequentially demographic and behavioral characteristics to better isolate the independent relationships between specific pathogens and depression.

The models estimating the probability of an individual reporting depression and the explanatory variables can be written as follows:

$$
\begin{gathered}
\operatorname{Pr}\left(\text { Depression }_{i}\right)=\boldsymbol{\phi}_{\boldsymbol{i}} \beta_{1}+\beta_{0}+\boldsymbol{\epsilon}_{i} \\
\operatorname{Pr}\left(\text { Depression }_{i}\right)=\boldsymbol{\phi}_{\boldsymbol{i}} \beta_{1}+\boldsymbol{\lambda}_{\boldsymbol{i}} \beta_{2}+\beta_{0}+\boldsymbol{\epsilon}_{i} \\
\operatorname{Pr}\left(\text { Depression }_{i}\right)=\boldsymbol{\phi}_{\boldsymbol{i}} \beta_{1}+\boldsymbol{\lambda}_{\boldsymbol{i}} \beta_{2}+\boldsymbol{\psi}_{\boldsymbol{i}} \beta_{3}+\beta_{0}+\boldsymbol{\epsilon}_{i}
\end{gathered}
$$

where $\phi_{i}$ represents a vector of binary indicators for whether individual $i$ reported experiencing each of the infection variables (Table 4 rows 1-6), $\lambda_{i}$ is a vector of indicators for participant characteristics of individual $i$ (Table 4 rows 7-18) and $\boldsymbol{\psi}_{i}$ is a vector of binary indicators for risk behaviors (Table 4 , rows 19-29). Unique coefficients for each of the infections $\beta_{1}$, each demographic characteristic $\beta_{2}$ and each risk behavior $\beta_{3}$ are reported in Table 4 . The $\beta_{0}$ represents the intercept, and $\epsilon_{i}$ represents a heteroskedasticity-robust individual error term. Analyses were conducted using the standard Stata packages logit, probit and regress for multiple logistic regression, probit regression and linear probability models, respectively.

This study was approved by the Institutional Review Boards at Bellarmine University (approval number 0313-3) and the University of Kentucky.

\section{Results}

\section{Depression}

A total of 1510 women met the inclusion criteria and provided information on mental health; $74 \%$ of them reported depression. Bivariate tests showed statistically significant positive associations of depression with Chlamydia trachomatis, Trichomonas vaginalis, abnormal pap smears, HPV, herpes simplex infections, endometriosis, infertility, frequent yeast infections and unspecified vaginal infections (Table 3). The sample size was sufficient to detect a statistically significant difference (at $p<0.002$ for a $2 \%$ difference in positivity) for each pathogen except for HIV and T. pallidum, for which there were only one and zero positive subjects, respectively.

The only pathogens that were significantly correlated with depression in the multiple regression analysis were $C$. trachomatis and $T$. vaginalis. Among the demographic variables, the only significant correlates of depression were use of antidepressants, being divorced and smoking cigarettes or 
Table 1. Information gathered from the registry

\begin{tabular}{lc}
\hline Category of information & \multicolumn{1}{c}{ Information recorded } \\
\hline $\begin{array}{c}\text { Demographic and } \\
\text { socioeconomic }\end{array}$ & $\begin{array}{c}\text { Age, race, marital status, level of education, annual household income, urban/rural } \\
\text { residence }\end{array}$ \\
\hline Lifestyle variables & $\begin{array}{c}\text { Use of tobacco, alcohol, marijuana, over-the-counter and prescription medications, } \\
\text { illegal drugs }\end{array}$ \\
\hline Gynecological health & $\begin{array}{c}\text { Chlamydia trachomatis, Neisseria gonorrhoeae, Treponema pallidum, Trichomonas } \\
\text { vaginalis, HIV, HPV, human herpes simplex 2, 'frequent yeast infections', 'frequent } \\
\text { vaginal infections', pelvic inflammatory disease, premenstrual syndrome/ } \\
\text { premenstrual dysphoric disorder }\end{array}$ \\
\hline
\end{tabular}

marijuana (Figure 1). Results are robust to alternative model specifications and standard logistic diagnostic tests for omission of high-leverage, standardized residuals and deviance.

We report results from heteroskedastic robust LPM for ease of interpretation, although $p$-values and other patterns are consistent across alternative modeling strategies, including probit and logistic regression models (Appendices 2 and 3, respectively).

Table 4 presents the results of the three LPM models indicating that the inclusion of more covariates highlights specific pathogens as substantively important predictors of reported depression. While several reported infection variables (HPV, frequent vaginal infections, C. trachomatis and T. vaginalis) are significant predictors in the model that account only for other infections (Table 4, column 1), the only infection variables that were significantly correlated with depression in the multiple regression analyses that account for the full set of demographic and behavioral covariates (Table 4, columns 2 and 3) are C. trachomatis and T. vaginalis, with magnitudes similar to those for headaches and pain. All else equal, each of these pathogens is associated with roughly a 10-percentage point increase (0.09 and 0.12, respectively) in the likelihood of reporting depression. Among the demographic and risk behavior variables, the only significant correlates of depression are use of antidepressants, alcohol, being divorced and smoking cigarettes. Associations of separation and marijuana usage are suggestive $(p<0.10)$ but not statistically significant. Figure 1 visually depicts the results of the most inclusive model (Table 4 column 3).

The previous study investigating associations between depression and sexually transmitted pathogens (Doyle et al. 2015) reported a significant association of depression with C. trachomatis and a nonsignificant association with $T$. vaginalis. Combined probability tests evaluating the overall findings of that study and the present one using the same (i.e. logistic) statistical model revealed a statistically significant association for C. trachomatis $\left(p<0.001, \chi^{2}=22.87\right.$, d.f. $\left.=4\right)$ and T. vaginalis $\left(p<0.05, \chi^{2}=9.79\right.$, d.f. $=4$ ), but not for any of the other pathogens. Depression occurred more frequently in women who reported infections with $C$. trachomatis and T. vaginalis $(89.5 \%)$ than with either $C$. trachomatis (57.5\%) or T. vaginalis $(45.8 \%)$ alone $\left(p<0.025, \chi^{2}=11.62\right.$, d.f. $\left.=4\right)$.

\section{Discussion}

Our results show that several sexually transmitted pathogens were significantly associated with depression by bivariate analyses; however, only two of the tested pathogens - Chlamydia trachomatis and Trichomonas vaginalis - were significantly associated with depression after correlations among infections and pathogens were accounted for by multiple regression analysis. C. trachomatis, T. vaginalis and the pathogens that were not significantly associated with depression generate inflammation (Georgescu et al. 2018; Hafner et al. 2014; Hube et al. 2015; Stevens and Criss 2018; Thurman and Doncel 2011). The results therefore support the hypothesis that depression results from specific effects of particular pathogens rather than from a general inflammatory response associated with infection. 
Table 2. Descriptive characteristics of the study population

\begin{tabular}{|c|c|}
\hline Demographic characteristics & $N(\%)$ \\
\hline \multicolumn{2}{|l|}{ Age } \\
\hline $18-24$ & $212(14 \%)$ \\
\hline $25-34$ & $822(54.4 \%)$ \\
\hline $35-40$ & $476(31.5 \%)$ \\
\hline \multicolumn{2}{|l|}{ Race } \\
\hline White & $1361(91.3 \%)$ \\
\hline Other & $130(8.7 \%)$ \\
\hline \multicolumn{2}{|l|}{ Marital status } \\
\hline Married & $859(57.2 \%)$ \\
\hline Separated & $45(3.0 \%)$ \\
\hline Divorced & $127(8.5 \%)$ \\
\hline Never married & $463(30.8 \%)$ \\
\hline \multicolumn{2}{|l|}{ Education } \\
\hline Some college, vocational/technical & $320(21.2 \%)$ \\
\hline Bachelor's degree & $409(27.1 \%)$ \\
\hline Postgraduate & $445(29.5 \%)$ \\
\hline \multicolumn{2}{|l|}{ Urban/rural } \\
\hline Urban & $982(65.3 \%)$ \\
\hline Rural & $521(34.7 \%)$ \\
\hline \multicolumn{2}{|l|}{ Appalachian } \\
\hline Yes & $334(22.2 \%)$ \\
\hline No & $1169(77.8 \%)$ \\
\hline
\end{tabular}

The lack of association between N. gonorrhoeae and depression is noteworthy because the pathologies of N. gonorrhoeae and C. trachomatis are similar. Each species can cause purulent discharges, pelvic inflammatory disease, oviduct inflammation and scarring, infertility and ectopic pregnancy (Hafner et al. 2014; Stevens and Criss 2018). If the depression associated with C. trachomatis resulted from the awareness of the presence of these manifestations, then $N$. gonorrhoeae should have been similarly associated with depression. This difference also bears on the lack of information in the database concerning the timing of knowledge about $C$. trachomatis infection relative to the timing of depression by weakening the possibility that its association with depression resulted from an effect of knowledge about a urethritis-associated sexually transmitted disease.

The inflammation associated with C. trachomatis and N. gonorrhoeae involves elevation of interferon gamma and activity of neutrophils (Hafner et al. 2014; Stevens and Criss 2018). Interferon gamma induces expression of indolamine 2,3-dioxygenase, which degrades tryptophan and thereby contributes to tryptophan restriction (Chen 2011; Ziklo et al. 2018). The difference between N. gonorrheae and C. trachomatis with respect to depression therefore cannot be attributed to the absence of this trigger for tryptophan restriction. Correlations between cytokines and depression are, however, complex, defying simple cause/effect explanations (Geisler et al. 2018). IDO1 and hence tryptophan can be controlled by different mechanisms, and C. trachomatis can elevate IDO1 independently of interferon gamma (Ziklo et al. 2019). 
Table 3. Bivariate associations between depression and sexually transmitted pathogens

\begin{tabular}{lccc}
\hline Agent or condition & Depression & & \\
Present & Absent & $p$-Value \\
\hline Chlamydia trachomatis & $80(8.2 \%)$ & $21(4.0 \%)$ & 0.002 \\
\hline Neisseria gonorrhoeae & $14(1.4 \%)$ & $4(0.8 \%)$ & 0.250 \\
\hline HPV & $146(15.1 \%)$ & $54(10.4 \%)$ & 0.01 \\
\hline Candida albicans & $78(8.0 \%)$ & $22(4.2 \%)$ & 0.004 \\
\hline Trichomonas vaginalis & $37(3.8 \%)$ & $2(0.4 \%)$ & $<0.0001$ \\
\hline Herpes simplex virus & $45(4.6 \%)$ & $16(3.1 \%)$ & 0.14 \\
\hline Pelvic Inflammatory Disease & $18(1.9 \%)$ & $5(1.0 \%)$ & 0.180 \\
\hline Frequent vaginal infections & $40(4.1 \%)$ & $6(1.13 \%)$ & 0.0014 \\
\hline
\end{tabular}

Note: Numbers refer to the total number of subjects that tested positive for the pathogen. Percentages in parentheses refer to the percentage of all subjects in the category that were positive for the specified pathogen. Too few reported positivity for T. pallidum and HIV to meet minimum sample sizes for statistical testing.

Upon tryptophan restriction in vitro, genital serovars of $C$. trachomatis enter a quiescent persistent phase (Aiyar et al. 2014). When indole is present, the tryptophan synthase of $C$. trachomatis generates tryptophan from the indole, allowing $C$. trachomatis to emerge from this quiescent phase to multiply and spread in the presence of tryptophan restriction (Aiyar et al. 2014). Inflammation associated with $N$. gonorrhoeae is not known to be associated with resistance to tryptophan restriction. The ability of C. trachomatis to persist in the presence of tryptophan restriction accords with the possibility that tryptophan restriction may be less effective in controlling C. trachomatis than N. gonorrhoeae and thus $C$. trachomatis may be associated with more persistent tryptophan restriction and, consequently, depression.

The hypothesized mechanism for an effect of C. trachomatis on depression presumes that tryptophan restriction at the sites of infection lowers tryptophan levels in the blood sufficiently to reduce serotonin synthesis in the brain. Lowered plasma concentrations of tryptophan are thought to reduce tryptophan in the brain as a result of the competition between amino acids at the blood-brain barrier (Fernstrom and Wurtman 1997; Pardridge 1979; Schiepers et al. 2005). As a result of this competition, even a small reduction in systemic tryptophan might lower serotonin synthesis in the brain (Fernstrom and Wurtman 1997). The greater the tryptophan sink is, however, the greater the potential for a reduction in serotonin synthesis. Serum concentrations of tryptophan average about $25 \%$ lower in depressed subjects than in subjects with normal mood (Cowen et al. 1989).

Persistent, systemic C. trachomatis infections should tend to generate a more substantial tryptophan sink and thus lower mood than infections that are restricted to the urogenital tissue. Reiter's syndrome is the main recognized category of systemic C. trachomatis disease. It is a persistent autoimmune disease that encompasses reactive arthritis and uveitis, with $C$. trachomatis being found in the joints and the conjunctiva of the eye, respectively (Haller-Schober and El-Shabrawi 2002; Rihl et al. 2006). C. trachomatis reaches the joints via infected monocytes or macrophages (Rihl et al. 2006). Infection of the eye occurs mainly through autoinoculation by urogenitally contaminated hands.

Integration of genetic associations of Reiter's syndrome provides a more comprehensive framework for evaluating the contribution of $C$. trachomatis to depression. The HLA-B27 allele is present in about $75 \%$ of subjects with sexually acquired Reiter's syndrome, which is caused mostly by C. trachomatis; the allele is present in about $90 \%$ of individuals with chronic disease (Baguley and Greenhouse 2003). Pathological effects of HLA-B27 appear to occur in response to microbes: HLA-B27 transgenic rats have inflammatory joint disease except when they are germ-free (Taurog et al. 1994). Depression has been found to be more common in uveitis patients who were HLA-B27 positive, with about 
Table 4. Linear probability models for variables associated with depression

\begin{tabular}{|c|c|c|c|}
\hline & (1) & (2) & (3) \\
\hline \multirow[t]{2}{*}{ C. trachomatis } & $0.098^{\star}$ & $0.089^{\star}$ & $0.096^{*}$ \\
\hline & {$[0.009-0.186]$} & {$[0.005-0.173]$} & {$[0.007-0.186]$} \\
\hline \multirow[t]{2}{*}{ Trichomonas vaginalis } & $0.240^{\star \star}$ & $0.173^{\star *}$ & $0.127^{\star}$ \\
\hline & {$[0.153-0.327]$} & {$[0.084-0.263]$} & {$[0.026-0.227]$} \\
\hline \multirow[t]{2}{*}{ Genital herpes } & 0.046 & 0.045 & 0.020 \\
\hline & {$[-0.069-0.160]$} & {$[-0.076-0.167]$} & {$[-0.099-0.138]$} \\
\hline \multirow[t]{2}{*}{ HPV } & $0.068^{*}$ & 0.038 & 0.000 \\
\hline & {$[0.000-0.136]$} & {$[-0.032-0.108]$} & {$[-0.071-0.072]$} \\
\hline \multirow[t]{2}{*}{ Neisseria gonorrhoea } & -0.010 & -0.089 & -0.109 \\
\hline & {$[-0.203-0.183]$} & {$[-0.278-0.100]$} & {$[-0.315-0.098]$} \\
\hline \multirow[t]{2}{*}{ Frequent vaginal infections } & $0.131^{\star}$ & $0.109 \dagger$ & 0.066 \\
\hline & {$[0.014-0.248]$} & {$[-0.016-0.234]$} & {$[-0.065-0.197]$} \\
\hline \multirow[t]{2}{*}{ Pain } & & $0.137^{\star \star}$ & $0.062^{*}$ \\
\hline & & {$[0.086-0.188]$} & {$[0.005-0.118]$} \\
\hline \multirow[t]{2}{*}{ Headaches } & & $0.153^{\star \star}$ & $0.153^{\star \star}$ \\
\hline & & {$[0.096-0.210]$} & {$[0.097-0.209]$} \\
\hline \multirow[t]{2}{*}{ Age } & & 0.004 & 0.003 \\
\hline & & {$[-0.001-0.009]$} & {$[-0.003-0.008]$} \\
\hline \multirow[t]{2}{*}{ Some college, vocational or technical } & & 0.023 & 0.007 \\
\hline & & {$[-0.064-0.111]$} & {$[-0.087-0.101]$} \\
\hline \multirow[t]{2}{*}{ Bachelors } & & 0.005 & -0.015 \\
\hline & & {$[-0.087-0.098]$} & {$[-0.116-0.086]$} \\
\hline \multirow[t]{2}{*}{ Postgraduate } & & -0.013 & -0.015 \\
\hline & & {$[-0.107-0.081]$} & {$[-0.117-0.087]$} \\
\hline \multirow[t]{2}{*}{ Separated } & & $0.188^{\star \star}$ & $0.131 \dagger$ \\
\hline & & {$[0.070-0.306]$} & {$[-0.005-0.267]$} \\
\hline \multirow[t]{2}{*}{ Divorced } & & $0.140^{\star *}$ & $0.124^{\star \star}$ \\
\hline & & {$[0.059-0.220]$} & [0.043-0.205] \\
\hline \multirow[t]{2}{*}{ Never married } & & 0.048 & 0.036 \\
\hline & & {$[-0.014-0.111]$} & {$[-0.028-0.100]$} \\
\hline \multirow[t]{2}{*}{ White } & & 0.027 & -0.010 \\
\hline & & {$[-0.058-0.112]$} & {$[-0.096-0.077]$} \\
\hline \multirow[t]{2}{*}{ Urban } & & 0.008 & -0.000 \\
\hline & & {$[-0.056-0.071]$} & {$[-0.065-0.064]$} \\
\hline \multirow[t]{2}{*}{ Appalachian } & & 0.026 & 0.016 \\
\hline & & {$[-0.046-0.098]$} & {$[-0.057-0.089]$} \\
\hline
\end{tabular}


Table 4. (Continued.)

\begin{tabular}{|c|c|c|c|}
\hline & (1) & (2) & (3) \\
\hline \multirow[t]{2}{*}{ Methamphetamine } & & & 0.187 \\
\hline & & & {$[-0.043-0.417]$} \\
\hline \multirow[t]{2}{*}{ Ecstasy } & & & -0.040 \\
\hline & & & {$[-0.237-0.156]$} \\
\hline \multirow[t]{2}{*}{ Heroin } & & & 0.020 \\
\hline & & & {$[-0.272-0.311]$} \\
\hline \multirow[t]{2}{*}{ Cocaine } & & & -0.151 \\
\hline & & & {$[-0.359-0.057]$} \\
\hline \multirow[t]{2}{*}{ Cigarettes } & & & $0.061^{\star}$ \\
\hline & & & [0.006-0.115] \\
\hline \multirow[t]{2}{*}{ Alcohol } & & & $0.068^{*}$ \\
\hline & & & {$[0.016-0.120]$} \\
\hline \multirow[t]{2}{*}{ Marijuana } & & & $0.084 \dagger$ \\
\hline & & & {$[-0.003-0.170]$} \\
\hline \multirow[t]{2}{*}{ Sleep medications } & & & 0.028 \\
\hline & & & {$[-0.035-0.091]$} \\
\hline \multirow[t]{2}{*}{ Antidepressants } & & & $0.256^{\star \star}$ \\
\hline & & & [0.200-0.311] \\
\hline \multirow[t]{2}{*}{ Stimulants } & & & 0.010 \\
\hline & & & {$[-0.074-0.094]$} \\
\hline \multirow[t]{2}{*}{ Diet pills } & & & -0.007 \\
\hline & & & {$[-0.184-0.169]$} \\
\hline$R^{2}$ & 0.02 & 0.08 & 0.14 \\
\hline$N$ & 1479 & 1430 & 1363 \\
\hline
\end{tabular}

Note: $95 \%$ confidence intervals based on Huber-White robust standard errors in brackets below coefficients from three separate LPMs. In column 1 depression is regressed on the six infection variables. Column 2 adds controls for headaches, pain, and demographic characteristics. Column 3 adds controls for risk behavior indicators. $\dagger p<0.1 ;{ }^{*} p<0.05 ;{ }^{\star *} p<0.01$.

half of these subjects being mildly or clinically depressed according to Beck Depression Inventory tests (scores $\geq 9$; Maca et al. 2011). These findings accord with the hypothesis that persistent, systemic C. trachomatis infections may particularly associated with depression. We expect that C. trachomatis-infected reactive arthritis patients would also be prone to depression, but to our knowledge this possibility has not been investigated.

The mechanistic reason for the association between T. vaginalis and depression is unclear, but T. vaginalis synthesizes indole which may be used by C. trachomatis as a substrate for synthesis of tryptophan (Aiyar et al. 2014; Lloyd et al.n 1991; Zubacova et al. 2011) and thus foster persistence of C. trachomatis (Ziklo et al. 2016). The higher frequency of depression among women who reported having both $C$. trachomatis and T. vaginalis infections is consistent with an exacerbating effect of T. vaginalis on C. trachomatis.

Our test focused on sexually transmitted pathogens because they tend to be persistent, but the arguments should apply to other pathogens that can persist in the presence of tryptophan restriction as a result of an ability to synthesize their own tryptophan. The presence of tryptophan synthase is not 


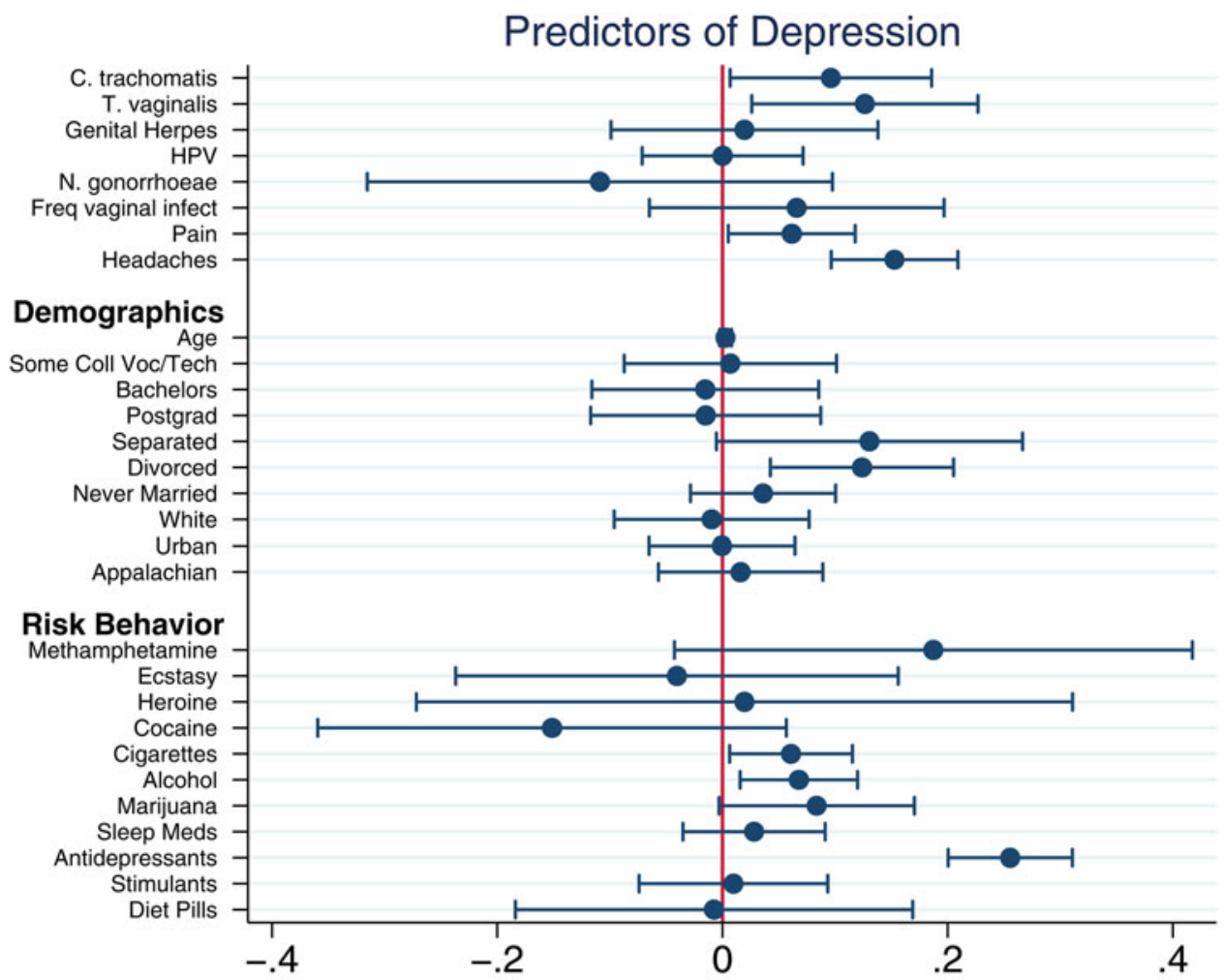

Coefficients and $95 \%$ Cls from linear probability model (LPM)

Figure 1. Linear probability model predicting reports of depression. Points represent coefficients from the most inclusive linear probability model (Table 4, column 3). Bars represent 95\% confidence intervals around each point. The first eight rows correspond to infection variables and two variables (pain and headaches) for which infection may be a contributing factor (Doyle et al., 2015).

necessarily an indicator of this ability - C. trachomatis is functional in the presence of tryptophan restriction by virtue of mutations in its tryptophan synthase operon (Somboonna et al. 2019), suggesting an evolutionary arms race between host abilities to silence tryptophan synthesis and the ability of C. trachomatis to circumvent this silencing. To our knowledge the only other pathogen for which tryptophan synthesis is known to be used as part of a persistence strategy is Mycobacterium tuberculosis, which upregulates tryptophan synthase upon infection of epithelial cells (Ryndak et al. 2015) and uses tryptophan-embedded phagosomal membranes to prevent fusion of the phagosome with lytic vesicles in macrophages, thereby evading intracellular destruction (Ferrari et al. 1999; Meena and Rajni 2010). Deletion of a tryptophan synthase gene in $M$. tuberculosis reduced persistence within macrophages in vitro as well as in lungs and spleen in a murine model (Smith et al. 2001). As is the case with C. trachomatis, failure of tryptophan restriction to resolve $M$. tuberculosis infection may therefore lead to persistent tryptophan restriction and low mood. Accordingly, depression is a major manifestation of tuberculosis (Ige and Lasebikan 2011).

The recognition that particular pathogens are associated with depression bears on the interpretation of drug effects. Minocycline, for example, ameliorates depression, an association that has been interpreted to result from its direct anti-inflammatory effects (Rosenblat and McIntyre 2018). Minocycline is effective against C. trachomatis (Romanowski et al. 1993) and M. tuberculosis (Deshpande et al. 2019) and could therefore ameliorate depression by controlling these pathogens. Our results therefore emphasize the need to evaluate the extent to which any ameliorative effects of antimicrobials are due to suppression of pathogens relative to direct suppression of inflammation. 
We think that the main value of our findings lies in indicating directions for future study. The correlational nature of our data do not allow us to assign cause and effect. Knowledge about the presence of C. trachomatis infection might have contributed to depression, even though the lack of an association of depression with $N$. gonorrhoeae indicates that knowledge about the presence of a C. trachomatis infection is insufficient to generate the observed association. The lack of adequate sample size for HIV and T. pallidum does not allow us to evaluate an association of these pathogens with depression. Each has been associated with depression but the psychological effects of knowledge of chronic syphilis or AIDS on mood has not been distinguished from direct effects of the pathogens on mood.

The absence of information on temporal sequence of depression and other variables in our database prevents an assessment of whether infection occurred before depression or vice versa. Women could have an infection without knowing it because infections are often asymptomatic (e.g. with N. gonorrhoeae and C. trachomatis) and may have erred in reporting depression or infectious conditions. These factors undoubtedly will create variability in the results but should not have generated the observed associations. The presence of an association of depression with $C$. trachomatis but the absence of such an association with N. gonorrhoeae serves as a control for these uncertainties, because the symptoms of these infections and the prevalence of asymptomatic relative to symptomatic infections are similar for these two pathogens. We note, however, that numbers of infected individuals were still relatively small, particularly for N. gonorrhoeae and T. vaginalis, a fact that could influence the outcome of statistical testing. Additional analyses with larger samples sizes and assessment of the temporal sequence of infection relative to depression will be useful.

Animal studies may provide a useful direction for evaluating cause and effect as well as the potential for generality of infectious causation of depression beyond humans. One limitation of animal models is the difficulty in knowing whether an animal is depressed. Social withdrawal could result from other phenomena, such as malaise, pain, distrust, fear or insecurity. One of the most reliable examples of infection-induced depression in another host species is sad horse disease, which is caused by borna disease virus and is associated with affect that corresponds to human depression (Tizard et al. 2016). In rats, borna disease virus infections of the central nervous system are associated with elevated IDO, suggesting that they also probably produce reductions in tryptophan (Formisano et al. 2017).

Animal models may also be helpful for evaluating alternative mechanisms. Mice infected with Bacille Calmette Guérin (= BCG, a strain derived from M. tuberculosis bovis) appear chronically depressed. BCG induced cytokines (TNF alpha and interferon gamma), which led to tryptophan catabolism via IDO. Accordingly, pre-treatment with an IDO inhibitor blocked BCG-induced depression, and IDO-deficient mice were resistant to BCG induction of depression even though they produced inflammatory cytokines associated with BCD infection (Moreau et al. 2005; O'Connor et al. 2009). These findings support a contribution of IDO activity to depression that is distinct from other effects of inflammatory cytokines.

Our results suggest that research needs to look beyond inflammation per se to processes associated with specific aspects of the inflammatory response, such as tryptophan restriction, and the effects of particular pathogens. The set of pathogens considered in this study was limited to those reported to the health registry. Our data set did not include, for example, cytomegalovirus infection, which causes persistent infections and has been correlated with depression in studies that did not find associations between depression and general markers of inflammation (Simanek et al. 2014; Simanek et al. 2018a, b). Cytomegalovirus has been associated with tryptophan degradation in vivo (Sadeghi et al. 2012). Similarly, H. pylori, which has been associated with depression in women (Simanek et al. 2018a), has also been associated with elevated levels of the tryptophan-degrading enzyme, IDO1 (Larussa et al. 2015). Each of these two pathogens can cause infections that may persist for decades and may therefore be associated with chronic lowering of tryptophan levels resulting in depressed mood.

The associations of particular persistent infectious agents (C. trachomatis, M. tuberculosis, H. pylori and cytomegalovirus) with depression, tryptophan depletion and resistance to tryptophan depletion support the hypothesis that at least some depression may result from evolutionary arms races with particular pathogens. The presence of tryptophan restriction by IDO1 in rodents suggests a deep 
evolutionary presence of this adaptation in placental mammals. More broadly, molecular phylogenies indicate that IDO1 and its high affinity for tryptophan occurs in monotremes, marsupials and placentals, but not in birds, amphibians or fish. This pattern suggests that IDO1 evolved its tryptophan catabolic functions in monotremes from an IDO2-like molecule (Yuasa et al. 2007; Yuasa et al. 2009). This pattern suggests that tryptophan restriction has evolved as a mammalian adaptation for regulating tryptophan and potentially as defense against pathogens before the divergence of these three groups of mammals. A short-term depressive effect on mood may have been a component of this defense by encouraging rest and recovery. Selection on pathogens to persist, however, apparently has led to persistent tryptophan restriction as an ineffective by-product of the adaptive response that is ineffective for the particular pathogens that evolved the upper hand in the evolutionary arms race associated with this defense. This interpretation together with the findings reported in this paper draw attention to the need for research on infection, inflammation and depression that encompasses the entire spectrum of persistent infectious agents with attention to the possible effects that particular pathogens have on depression through induction of persistent tryptophan restriction.

Data availability statement. The data that support the findings of this study are available from The University of Kentucky's Wellness, Health and You data resource (https://www.wellnesshealthandyou.org), formerly the Kentucky Women's Health Registry. Restrictions apply to the availability of these data. A data use agreement was signed to allow use by the authors and thus are not publicly available from the authors.

Acknowledgements. This research was made possible by Wellness, Health and You (WHY) and the volunteers who graciously participated in this health survey. The primary investigators for the WHY survey are Heather Bush, $\mathrm{PhD}$ and Ann L. Coker, PhD. The WHY project is based at the University of Kentucky and has been supported by the National Center for Research Resources and the National Center for Advancing Translational Sciences, National Institutes of Health, through grant UL1TR001998. The content of the database is solely the responsibility of the WHY investigators and does not necessarily represent the official views of the NIH. The authors thank Candace Brancato at WHY for extracting data and performing the first round of bivariate tests for the current study.

Author contributions. C.M.D., P.W.E. and H.A.S. generated the conceptual framework for the paper and reviewed the literature. H.S.E. originated and developed the connection between tryptophan restriction and depression. C.M.D arranged for access to the database and ran the final bivariate tests. C.M.D. and P.W.E contributed equally to manuscript preparation and conducted the combined probability analyses. W.A.S. performed the multivariate analysis and wrote the corresponding portions of the Methods and Results sections.

Financial support. This research received no specific grant from any funding agency, commercial or not-for-profit sectors.

Publishing ethics. All authors declare that the manuscript is their own original work and does not duplicate another published work. The manuscript has been submitted only to this journal - it is not under consideration, accepted for publication or in press elsewhere. All listed authors know of and agree to the manuscript being submitted to the journal. The manuscript contains nothing that is abusive, defamatory, fraudulent, illegal, libelous or obscene.

Conflicts of interest. C.M.D., W.A.S., H.A.S., and P.W.E declare no conflict of interests.

\section{References}

Aiyar A, Quayle AJ, Buckner LR, Sherchand SP, Chang TL, Zea AH, Martin DH and Belland RJ (2014) Influence of the tryptophan-indole-IFNgamma axis on human genital Chlamydia trachomatis infection: role of vaginal co-infections. Frontiers in Cellular and Infection Microbiology 4, 72. doi:10.3389/fcimb.2014.00072

Akers JC and Tan M (2006) Molecular mechanism of tryptophan-dependent transcriptional regulation in Chlamydia trachomatis. Journal of Bacteriology 188(12), 4236-4243. doi:10.1128/JB.01660-05

American Psychiatric Association (2013) Diagnostic and Statistical Manual of Mental Disorders (5th edn). Arlington, VA: American Psychiatric Publishing.

Anders S, Tanaka M and Kinney DK (2013) Depression as an evolutionary strategy for defense against infection. Brain, Behavior and Immunology 31, 9-22. doi:10.1016/j.bbi.2012.12.002

Baguley S and Greenhouse P (2003) Non-genital manifestations of Chlamydia trachomatis. Clinical Medicine (London) 3(3), 206-208. doi:10.7861/clinmedicine.3-3-206

Baune BT (2017) Are non-steroidal anti-inflammatory drugs clinically suitable for the treatment of symptoms in depressionassociated inflammation? Current Topics in Behavior and Neuroscience 31, 303-319. doi:10.1007/7854_2016_19 
Benros ME, Waltoft BL, Nordentoft M, Ostergaard SD, Eaton WW, Krogh J and Mortensen PB (2013) Autoimmune diseases and severe infections as risk factors for mood disorders: a nationwide study. JAMA Psychiatry 70(8), 812-820. doi:10.1001/jamapsychiatry.2013.1111

Canli T (2014) Reconceptualizing major depressive disorder as an infectious disease. Biology of Mood and Anxiety Disorders 4, 10. doi:10.1186/2045-5380-4-10

Chen W (2011) IDO: more than an enzyme. Nature Immunology 12(9), 809-811. doi:10.1038/ni.2088

Cowen PJ, Parry-Billings M and Newsholme EA (1989) Decreased plasma tryptophan levels in major depression. Journal of Affective Disorders 16(1), 27-31.

Coyne J (2010) The evolutionary calculus of depression. Psychiatric Times 27(8), 32-33.

Cubala WJ and Landowski J (2014) C-reactive protein and cortisol in drug-naive patients with short-illness-duration first episode major depressive disorder: possible role of cortisol immunomodulatory action at early stage of the disease. Journal of Affective Disorders 152-154, 534-537. doi:10.1016/j.jad.2013.10.004

Deshpande D, Pasipanodya JG, Srivastava S, Martin KR, Athale S, van Zyl J, Antiabong J, Koeuth T, Lee PS, Dheda K and Gumbo T (2019) Minocycline immunomodulates via sonic hedgehog signaling and apoptosis and has direct potency against drug-resistant tuberculosis. Journal of Infectious Disease 219(6), 975-985. doi:10.1093/infdis/jiy587

Dodd SM, Pereira DB, Marion I, Andrasik M, Rose R, Simon T, Fletcher MA, Lucci J, Maher K, O’Sullivan MJ, EfantisPotter J and Antoni MH (2009) Depressive symptoms and cervical neoplasia in HIV+ low-income minority women with human papillomavirus infection. International Journal of Behavioral Medicine 16(2), 181-188. doi:10.1007/s12529-0089025-1

Doyle C, Ewald HA and Ewald PW (2007) Premenstrual syndrome: an evolutionary perspective on its causes and treatment. Perspectives on Biology and Medicine 50(2), 181-202. doi:S1529879507201814 [pii]10.1353/pbm.2007.0015

Doyle C, Swain WA, Ewald HA, Cook CL and Ewald PW (2015) Sexually transmitted pathogens, depression, and other manifestations associated with premenstrual syndrome. Human Nature 26(3), 277-291. doi:10.1007/s12110-015-9238-3

Ewald PW (1980) Evolutionary biology and the treatment of signs and symptoms of infectious disease. Journal of Theoretical Biology 86(1), 169-176.

Eyre HA, Air T, Proctor S, Rositano S and Baune BT (2015) A critical review of the efficacy of non-steroidal antiinflammatory drugs in depression. Progress in Neuropsychopharmacology, Biology and Psychiatry 57, 11-16. doi:10.1016/j.pnpbp.2014.10.003

Fakhoury M (2016) Revisiting the serotonin hypothesis: implications for major depressive disorders. Molecular Neurobiology 53(5), 2778-2786. doi:10.1007/s12035-015-9152-Z

Fernstrom JD and Wurtman RJ (1997) Brain serotonin content: physiological regulation by plasma neutral amino acids. Obesity Research 5(4), 377-380.

Ferrari G, Langen H, Naito M and Pieters J (1999) A coat protein on phagosomes involved in the intracellular survival of mycobacteria. Cell 97(4), 435-447.

Formisano S, Hornig M, Yaddanapudi K, Vasishtha M, Parsons LH, Briese T, Lipkin WI and Williams BL (2017) Central nervous system infection with borna disease virus causes kynurenine pathway dysregulation and neurotoxic quinolinic acid production. Journal of Virology 91(14). DOI: 10.1128/JVI.00673-17.

Galecki P and Talarowska M (2017) The evolutionary theory of depression. Medical Science Monitoring 23, $2267-2274$.

Geisler S, Sperner-Unterweger B, Fuchs D and Gostner JM (2018) Immunometabolism in the pathogenesis of depressive disorders - therapeutic considerations. Current Topics in Medical Chemistry 18(16), 1408-1415. doi:10.2174/ 1568026618666180410141042

Georgescu SR, Mitran CI, Mitran MI, Caruntu C, Sarbu MI, Matei C, Nicolae i, Tocut SM, Popa MI and Tampa M (2018) New insights in the pathogenesis of HPV infection and the associated carcinogenic processes: the role of chronic inflammation and oxidative stress. Journal of Immunology Research 2018, 5315816. 10.1155/2018/5315816.

Hafner LM, Wilson DP and Timms P (2014) Development status and future prospects for a vaccine against Chlamydia trachomatis infection. Vaccine 32(14), 1563-1571. doi:10.1016/j.vaccine.2013.08.020

Haller-Schober EM and El-Shabrawi Y (2002) Chlamydial conjunctivitis (in adults), uveitis, and reactive arthritis, including SARA. Sexually acquired reactive arthritis. Best Practice Research in Clinical Obstetrics and Gynaecology 16(6), 815-828.

Hrboticky N, Leiter LA and Anderson GH (1989) Menstrual cycle effects on the metabolism of tryptophan loads. The American Journal of Clinical Nutrition 50(1), 46-52.

Hube B, Hay R, Brasch J, Veraldi S and Schaller M (2015) Dermatomycoses and inflammation: the adaptive balance between growth, damage, and survival. Journal of Mycological Medicine 25(1), e44-58. doi:10.1016/j.mycmed.2014.11.002

Ige OM and Lasebikan VO (2011) Prevalence of depression in tuberculosis patients in comparison with non-tuberculosis family contacts visiting the DOTS clinic in a Nigerian tertiary care hospital and its correlation with disease pattern. Mental Health and Family Medicine 8(4), 235-241.

Khandaker GM, Pearson RM, Zammit S, Lewis G and Jones PB (2014) Association of serum interleukin 6 and C-reactive protein in childhood with depression and psychosis in young adult life: a population-based longitudinal study. JAMA Psychiatry 71(10), 1121-1128. doi:10.1001/jamapsychiatry.2014.1332 
Kinney DK and Tanaka M (2009) An evolutionary hypothesis of depression and its symptoms, adaptive value, and risk factors. Journal of Nervous and Mental Diseases 197(8), 561-567. doi:10.1097/NMD.0b013e3181b05fa8

Kohler O, Benros ME, Nordentoft M, Farkouh ME, Iyengar RL, Mors O and Krogh J (2014) Effect of anti-inflammatory treatment on depression, depressive symptoms, and adverse effects: a systematic review and meta-analysis of randomized clinical trials. JAMA Psychiatry 71(12), 1381-1391. doi:10.1001/jamapsychiatry.2014.1611

Kohler O, Krogh J, Mors O and Benros ME (2016a) Inflammation in depression and the potential for anti-inflammatory treatment. Current Neuropharmacology 14(7), 732-742.

Kohler S, Cierpinsky K, Kronenberg G and Adli M (2016b) The serotonergic system in the neurobiology of depression: Relevance for novel antidepressants. Journal of Psychopharmacology 30(1), 13-22. doi:10.1177/0269881115609072

Kupfer DJ, Frank E and Phillips ML (2012) Major depressive disorder: new clinical, neurobiological, and treatment perspectives. Lancet 379(9820), 1045-1055. doi:10.1016/S0140-6736(11)60602-8

Larussa T, Leone I, Suraci E, Nazionale I, Procopio T, Conforti F, Abenavoli L, Hribal ML, Imeneo M and Luzza F (2015) Enhanced expression of indoleamine 2,3-dioxygenase in Helicobacter pylori-infected human gastric mucosa modulates Th1/Th2 pathway and interleukin 17 production. Helicobacter 20(1), 41-48. doi:10.1111/hel.12174

Lloyd D, Lauritsen FR and Degn H (1991) The parasitic flagellates Trichomonas vaginalis and Tritrichomonas foetus produce indole and dimethyl disulphide: direct characterization by membrane inlet tandem mass spectrometry. Journal of General Microbiology 137(7), 1743-1747. doi:10.1099/00221287-137-7-1743

Lopez CR, Antoni MH, Pereira D, Seay J, Whitehead N, Potter J, O'Sullivan M and Fletcher MA (2013) Stress management, depression and immune status in lower income racial/ethnic minority women co-infected with HIV and HPV. Journal of Applied Biobehavior Research 18(1), 37-57. doi:10.1111/jabr.12003

Maca SM, Schiesser AW, Sobala A, Gruber K, Pakesch G, Prause C and Barisani-Asenbauer T (2011) Distress, depression and coping in HLA-B27-associated anterior uveitis with focus on gender differences. British Journal of Ophthalmology 95(5), 699-704. doi:10.1136/bjo.2009.174839

Maes M, Yirmyia R, Noraberg J, Brene S, Hibbeln J, Perini G, Kubera M, Bob P, Lerer B and Maj M (2009) The inflammatory \& neurodegenerative (I\&ND) hypothesis of depression: leads for future research and new drug developments in depression. Metabolic and Brain Disease 24(1), 27-53. doi:10.1007/s11011-008-9118-1

Meena LS and Rajni (2010) Survival mechanisms of pathogenic Mycobacterium tuberculosis H37Rv. FEBS J, 277(11), 24162427. doi:10.1111/j.1742-4658.2010.07666.x

Miller AH, Maletic V and Raison CL (2009) Inflammation and its discontents: the role of cytokines in the pathophysiology of major depression. Biological Psychiatry 65(9), 732-741. doi:10.1016/j.biopsych.2008.11.029

Moreau M, Lestage J, Verrier D, Mormede C, Kelley KW, Dantzer R and Castanon N (2005) Bacille Calmette-Guerin inoculation induces chronic activation of peripheral and brain indoleamine 2,3-dioxygenase in mice. Journal of Infectious Disease 192(3), 537-544. doi:10.1086/431603

Nesse RM (2019) Good Reasons for Bad Feelings. Insights from the Frontier of Evolutionary Psychiatry. New York: Dutton.

O'Connor JC, Lawson MA, Andre C, Briley EM, Szegedi SS, Lestage J, Castanon N, Herkenham M, Dantzer R and Kelley KW (2009) Induction of IDO by bacille Calmette-Guerin is responsible for development of murine depressive-like behavior. Journal of Immunology 182(5), 3202-3212. doi:10.4049/jimmunol.0802722

Olive AJ and Sassetti CM (2016) Metabolic crosstalk between host and pathogen: sensing, adapting and competing. Nature Reviews in Microbiology 14(4), 221-234. doi:10.1038/nrmicro.2016.12

Pardridge WM (1979) The role of blood-brain barrier transport of tryptophan and other neutral amino acids in the regulation of substrate-limited pathways of brain amino acid metabolism. Journal of Neural Transmission Supplements 15, 43-54.

Pasco JA, Jacka FN, Williams LJ, Henry MJ, Nicholson GC, Kotowicz MA and Berk M (2010a) Clinical implications of the cytokine hypothesis of depression: the association between use of statins and aspirin and the risk of major depression. Psychotherapy and Psychosomatics 79(5), 323-325. doi:10.1159/000319530

Pasco JA, Nicholson GC, Williams LJ, Jacka FN, Henry MJ, Kotowicz MA, Schneider HG, Leonard BE and Berk M (2010b) Association of high-sensitivity C-reactive protein with de novo major depression. British Journal of Psychiatry 197(5), 372-377. doi:10.1192/bjp.bp.109.076430

Raison CL and Miller AH (2013a) Do cytokines really sing the blues? Cerebrum 2013, 10.

Raison CL and Miller AH (2013b) The evolutionary significance of depression in Pathogen Host Defense (PATHOS-D). Molecular Psychiatry 18(1), 15-37. doi:10.1038/mp.2012.2

Raison CL, Rutherford RE, Woolwine BJ, Shuo C, Schettler P, Drake DF, Haroon E and Miller AH (2013) A randomized controlled trial of the tumor necrosis factor antagonist infliximab for treatment-resistant depression: the role of baseline inflammatory biomarkers. JAMA Psychiatry 70(1), 31-41.

Rihl M, Kohler L, Klos A and Zeidler H (2006) Persistent infection of Chlamydia in reactive arthritis. Annals of Rheumatic Disease 65(3), 281-284. doi:10.1136/ard.2005.044966

Romanowski B, Talbot H, Stadnyk M, Kowalchuk P and Bowie WR (1993) Minocycline compared with doxycycline in the treatment of nongonococcal urethritis and mucopurulent cervicitis. Annals of Internal Medicine 119(1), 16-22.

Rosenblat JD and McIntyre RS (2018) Efficacy and tolerability of minocycline for depression: a systematic review and meta-analysis of clinical trials. Journal of Affective Disorder 227, 219-225. doi:10.1016/j.jad.2017.10.042 
Ryndak MB, Singh KK, Peng Z and Laal S (2015) Transcriptional profile of Mycobacterium tuberculosis replicating in type II alveolar epithelial cells. PLoS One 10(4), e0123745. doi:10.1371/journal.pone.0123745

Sadeghi M, Lahdou I, Daniel V, Schnitzler P, Fusch G, Schefold JC, Zeier M, Iancu M, Opelz G and Terness P (2012) Strong association of phenylalanine and tryptophan metabolites with activated cytomegalovirus infection in kidney transplant recipients. Human Immunology 73(2), 186-192. doi:10.1016/j.humimm.2011.11.002

Schiepers OJ, Wichers MC and Maes M (2005) Cytokines and major depression. Progress in Neuropsychopharmacology and Biological Psychiatry 29(2), 201-217. doi:10.1016/j.pnpbp.2004.11.003

Schmidt SV and Schultze JL (2014) New insights into IDO biology in bacterial and viral infections. Frontiers in Immunology 5, 384. doi:10.3389/fimmu.2014.00384

Simanek AM, Cheng C, Yolken R, Uddin M, Galea S and Aiello AE (2014) Herpes viruses, inflammatory markers and incident depression in a longitudinal study of Detroit residents. Psychoneuroendocrinology 50, 139-148. doi:10.1016/ j.psyneuen.2014.08.002

Simanek AM, Parry A and Dowd JB (2018a) Differences in the association between persistent pathogens and mood disorders among young- to middle-aged women and men in the U.S. Brain Behavior and Immunology 68, 56-65. doi:10.1016/ j.bbi.2017.09.017

Simanek AM, Zheng C, Yolken R, Haan M and Aiello AE (2018b) A longitudinal study of the association between persistent pathogens and incident depression among older US Latinos. Journal of Gerontology A: Biological Science and Medical Science 74(5), 634-641. doi:10.1093/gerona/gly172

Smith DA, Parish T, Stoker NG and Bancroft GJ (2001) Characterization of auxotrophic mutants of Mycobacterium tuberculosis and their potential as vaccine candidates. Infectious Immunology 69(2), 1142-1150. doi:10.1128/ IAI.69.2.1442-1150.2001

Somboonna N, Ziklo N, Ferrin TE, Hyuk Suh J and Dean D (2019) Clinical persistence of Chlamydia trachomatis sexually transmitted strains involves novel mutations in the functional alphabetabetaalpha tetramer of the tryptophan synthase operon. MBio 10(4), e01464-19. doi:10.1128/mBio.01464-19

Stevens JS and Criss AK (2018) Pathogenesis of Neisseria gonorrhoeae in the female reproductive tract: neutrophilic host response, sustained infection, and clinical sequelae. Current Opinion on Hematology 25(1), 13-21. doi:10.1097/ MOH.0000000000000394

Taurog JD, Richardson JA, Croft JT, Simmons WA, Zhou M, Fernandez-Sueiro JL, Balish E and Hammer RE (1994) The germfree state prevents development of gut and joint inflammatory disease in HLA-B27 transgenic rats. Journal of Experimental Medicine 180(6), 2359-2364. doi:10.1084/jem.180.6.2359

Thurman AR and Doncel GF (2011) Innate immunity and inflammatory response to Trichomonas vaginalis and bacterial vaginosis: relationship to HIV acquisition. American Journal of Reproductive Immunology 65(2), 89-98. doi:10.1111/ j.1600-0897.2010.00902.x

Tizard I, Ball J, Stoica G and Payne S (2016) The pathogenesis of bornaviral diseases in mammals. Animal Health Research Review 17(2), 92-109. doi:10.1017/S1466252316000062

Wang X, Zhang L, Lei Y, Liu X, Zhou X, Liu Y, Wang M, Yang L, Zhang L, Fan S and Xie P (2014) Meta-analysis of infectious agents and depression. Science Reports 4, 4530. doi:10.1038/srep04530

Xiao BG, Liu X and Link H (2004) Antigen-specific T cell functions are suppressed over the estrogen-dendritic cell-indoleamine 2,3-dioxygenase axis. Steroids 69(10), 653-659. doi:10.1016/j.steroids.2004.05.019

Yuasa HJ, Takubo M, Takahashi A, Hasegawa T, Noma H and Suzuki T (2007) Evolution of vertebrate indoleamine 2,3dioxygenases. Journal of Molecular Evolution 65(6), 705-714.

Yuasa HJ, Ball HJ, Ho YF, Austin CJ, Whittington CM, Belov K, Maghzal GJ, Jermiin LS and Hunt NH (2009) Characterization and evolution of vertebrate indoleamine 2,3-dioxygenases IDOs from monotremes and marsupials. Comparative Biochemistry and Physiology. Part B 153(2), 137-144.

Ziklo N, Huston WM, Taing K, Katouli M and Timms P (2016) In vitro rescue of genital strains of Chlamydia trachomatis from interferon-gamma and tryptophan depletion with indole-positive, but not indole-negative Prevotella spp. BMC Microbiology 16(1), 286. doi:10.1186/s12866-016-0903-4

Ziklo N, Vidgen ME, Taing K, Huston WM and Timms P (2018) Dysbiosis of the vaginal microbiota and higher vaginal kynurenine/tryptophan ratio reveals an association with Chlamydia trachomatis Genital Infections. Frontiers in Cellular and Infectious Microbiology 8, 1. doi:10.3389/fcimb.2018.00001

Ziklo N, Huston WM, Taing K and Timms P (2019) High expression of IDO1 and TGF-betal during recurrence and post infection clearance with Chlamydia trachomatis, are independent of host IFN-gamma response. BMC Infectious Diseases 19(1), 218. doi:10.1186/s12879-019-3843-4

Zubacova Z, Krylov V and Tachezy J (2011) Fluorescence in situ hybridization (FISH) mapping of single copy genes on Trichomonas vaginalis chromosomes. Molecular Biochemistry and Parasitology 176(2), 135-137. doi:10.1016/ j.molbiopara.2010.12.011 
Appendix 1: Questions from the Kentucky Women's Health Registry survey version 8.1 related to depression and infection

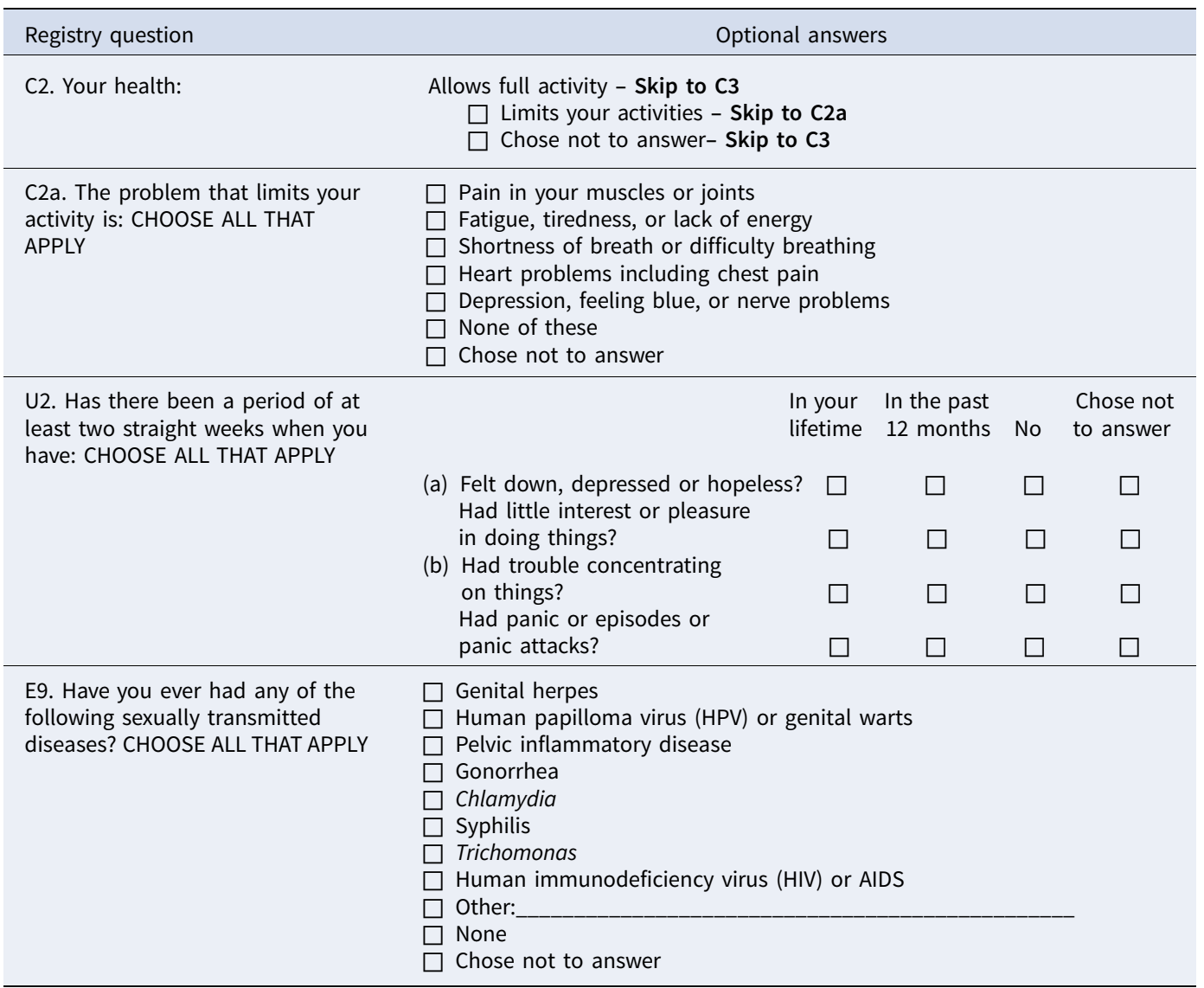

\section{Appendix 2: Probit estimates of association with depression}

\begin{tabular}{lcccc}
\hline & Probit 1 & Probit 2 & Probit 3 \\
\hline Chlamydia trachomatis & $0.329^{*}$ & $0.347^{*}$ & $0.416^{*}$ \\
\hline & $(0.151)$ & $(0.165)$ & $(0.202)$ \\
\hline Trichomonas vaginalis & $1.135^{\star *}$ & $1.007^{\star *}$ & $0.792^{\star}$ \\
\hline Genital herpes & $(0.346)$ & $(0.348)$ & $(0.370)$ \\
\hline HPV & 0.129 & 0.105 & 0.022 \\
\hline & $(0.183)$ & $(0.202)$ & $(0.222)$ \\
\hline Neisseria gonorrhoeae & $0.195 \dagger$ & 0.119 & 0.003 \\
\hline & $(0.104)$ & $(0.109)$ & $(0.121)$ \\
\hline Frequent vaginal infections & 0.056 & -0.252 & -0.348 \\
\hline & $(0.349)$ & $(0.338)$ & $(0.356)$ \\
\hline
\end{tabular}


Appendix 2: (Continued.)

\begin{tabular}{|c|c|c|}
\hline & Probit 1 & Probit 3 \\
\hline \multirow[t]{2}{*}{ Pain } & $0.384^{\star \star}$ & $0.161^{*}$ \\
\hline & $(0.072)$ & $(0.080)$ \\
\hline \multirow[t]{2}{*}{ Headaches } & $0.413^{\star \star}$ & $0.438^{\star \star}$ \\
\hline & $(0.078)$ & $(0.082)$ \\
\hline \multirow[t]{2}{*}{ Age } & 0.010 & 0.007 \\
\hline & $(0.008)$ & $(0.008)$ \\
\hline \multirow[t]{2}{*}{ Some college, vocational/technical } & 0.082 & 0.055 \\
\hline & $(0.136)$ & $(0.155)$ \\
\hline \multirow[t]{2}{*}{ Bachelors } & 0.027 & -0.011 \\
\hline & $(0.139)$ & $(0.162)$ \\
\hline \multirow[t]{2}{*}{ Postgraduate } & -0.026 & -0.009 \\
\hline & $(0.140)$ & $(0.163)$ \\
\hline \multirow[t]{2}{*}{ Separated } & $0.669^{*}$ & 0.495 \\
\hline & $(0.276)$ & $(0.304)$ \\
\hline \multirow[t]{2}{*}{ Divorced } & $0.455^{\star \star}$ & $0.464^{\star *}$ \\
\hline & $(0.149)$ & $(0.163)$ \\
\hline \multirow[t]{2}{*}{ Never married } & 0.128 & 0.095 \\
\hline & $(0.091)$ & $(0.098)$ \\
\hline \multirow[t]{2}{*}{ White } & 0.086 & -0.022 \\
\hline & $(0.127)$ & $(0.133)$ \\
\hline \multirow[t]{2}{*}{ Urban } & 0.027 & 0.025 \\
\hline & $(0.094)$ & $(0.100)$ \\
\hline \multirow[t]{2}{*}{ Appalachian } & 0.073 & 0.062 \\
\hline & $(0.107)$ & $(0.113)$ \\
\hline \multirow[t]{2}{*}{ Ecstasy } & & 0.017 \\
\hline & & $(0.584)$ \\
\hline \multirow[t]{2}{*}{ Heroin } & & -0.264 \\
\hline & & $(0.735)$ \\
\hline \multirow[t]{2}{*}{ Cocaine } & & -0.582 \\
\hline & & $(0.386)$ \\
\hline \multirow[t]{2}{*}{ Cigarettes } & & $0.184^{\star}$ \\
\hline & & $(0.087)$ \\
\hline \multirow[t]{2}{*}{ Alcohol } & & $0.186^{\star}$ \\
\hline & & $(0.080)$ \\
\hline \multirow[t]{2}{*}{ Marijuana } & & $0.286 \dagger$ \\
\hline & & $(0.164)$ \\
\hline Sleep medicines & & 0.132 \\
\hline
\end{tabular}


Appendix 2: (Continued.)

\begin{tabular}{|c|c|c|c|}
\hline & Probit 1 & Probit 2 & Probit 3 \\
\hline & & & $(0.113)$ \\
\hline \multirow[t]{2}{*}{ Antidepressants } & & & $0.933^{\star *}$ \\
\hline & & & $(0.123)$ \\
\hline \multirow[t]{2}{*}{ Stimulants } & & & 0.099 \\
\hline & & & $(0.173)$ \\
\hline \multirow[t]{2}{*}{ Diet pills } & & & -0.005 \\
\hline & & & $(0.310)$ \\
\hline$N$ & 1479 & 1430 & 1353 \\
\hline
\end{tabular}

Note. Models mirror those described in Table 4 in the body of the text. Huber-White robust standard errors in parentheses. Coefficients from probit model. $\dagger p<0.1 ;{ }^{\star} p<0.05 ;{ }^{* \star} p<0.01$

Appendix 3: logit estimates of association with depression

\begin{tabular}{|c|c|c|c|}
\hline & Logit 1 & Logit 2 & Logit 3 \\
\hline \multirow[t]{2}{*}{ Chlamydia trachomatis } & $1.715^{\star}$ & $1.776^{\star}$ & $2.107^{\star}$ \\
\hline & $(2.08)$ & $(2.02)$ & $(2.10)$ \\
\hline \multirow[t]{2}{*}{ Trichomonas vaginalis } & $7.846^{\star \star}$ & $5.979^{\star}$ & $3.847 \dagger$ \\
\hline & $(2.81)$ & $(2.46)$ & $(1.86)$ \\
\hline \multirow[t]{2}{*}{ Genital herpes } & 1.250 & 1.236 & 1.058 \\
\hline & $(0.72)$ & $(0.61)$ & $(0.15)$ \\
\hline \multirow[t]{2}{*}{ HPV } & $1.387 \dagger$ & 1.222 & 1.000 \\
\hline & $(1.89)$ & $(1.09)$ & $(0.00)$ \\
\hline \multirow[t]{2}{*}{ Neisseria gonorrhoeae } & 1.066 & 0.616 & 0.524 \\
\hline & $(0.11)$ & $(0.89)$ & $(1.12)$ \\
\hline \multirow[t]{2}{*}{ Frequent vaginal infections } & $2.444 \dagger$ & 2.145 & 1.601 \\
\hline & $(1.94)$ & $(1.53)$ & $(0.92)$ \\
\hline \multirow[t]{2}{*}{ Pain } & & $1.871^{\star \star}$ & $1.288 \dagger$ \\
\hline & & $(5.31)$ & $(1.91)$ \\
\hline \multirow[t]{2}{*}{ Headaches } & & $1.956^{\star \star}$ & $2.061^{\star *}$ \\
\hline & & $(5.29)$ & $(5.30)$ \\
\hline \multirow[t]{2}{*}{ Age } & & 1.017 & 1.011 \\
\hline & & $(1.37)$ & $(0.84)$ \\
\hline \multirow[t]{2}{*}{ Some college, vocational/technical } & & 1.135 & 1.063 \\
\hline & & $(0.56)$ & $(0.24)$ \\
\hline \multirow[t]{2}{*}{ Bachelors } & & 1.040 & 0.958 \\
\hline & & $(0.17)$ & $(0.16)$ \\
\hline \multirow[t]{2}{*}{ Postgraduate } & & 0.964 & 0.948 \\
\hline & & $(0.16)$ & $(0.19)$ \\
\hline
\end{tabular}


Appendix 3: (Continued.)

\begin{tabular}{|c|c|c|c|}
\hline & Logit 1 & Logit 2 & Logit 3 \\
\hline \multirow[t]{2}{*}{ Separated } & & $3.295^{\star}$ & 2.409 \\
\hline & & $(2.30)$ & $(1.57)$ \\
\hline \multirow[t]{2}{*}{ Divorced } & & $2.203^{\star \star}$ & $2.172^{\star \star}$ \\
\hline & & $(3.01)$ & $(2.70)$ \\
\hline \multirow[t]{2}{*}{ Never married } & & 1.251 & 1.146 \\
\hline & & $(1.47)$ & $(0.83)$ \\
\hline \multirow[t]{2}{*}{ White } & & 1.156 & 0.974 \\
\hline & & $(0.69)$ & $(0.12)$ \\
\hline \multirow[t]{2}{*}{ Urban } & & 1.035 & 1.038 \\
\hline & & $(0.23)$ & $(0.22)$ \\
\hline \multirow[t]{2}{*}{ Appalachian } & & 1.125 & 1.106 \\
\hline & & $(0.67)$ & $(0.53)$ \\
\hline \multirow[t]{2}{*}{ Ecstasy } & & & 0.963 \\
\hline & & & $(0.04)$ \\
\hline \multirow[t]{2}{*}{ Heroin } & & & 0.561 \\
\hline & & & $(0.43)$ \\
\hline \multirow[t]{2}{*}{ Cocaine } & & & 0.385 \\
\hline & & & $(1.37)$ \\
\hline \multirow[t]{2}{*}{ Cigarettes } & & & $1.367^{\star}$ \\
\hline & & & $(2.16)$ \\
\hline \multirow[t]{2}{*}{ Alcohol } & & & $1.364^{\star}$ \\
\hline & & & $(2.34)$ \\
\hline \multirow[t]{2}{*}{ Marijuana } & & & $1.754^{\star}$ \\
\hline & & & $(1.97)$ \\
\hline \multirow[t]{2}{*}{ Sleep medicines } & & & 1.268 \\
\hline & & & $(1.23)$ \\
\hline \multirow[t]{2}{*}{ Antidepressants } & & & $5.179^{\star \star}$ \\
\hline & & & (7.34) \\
\hline \multirow[t]{2}{*}{ Stimulants } & & & 1.196 \\
\hline & & & $(0.60)$ \\
\hline \multirow[t]{2}{*}{ Diet pills } & & & 1.029 \\
\hline & & & $(0.05)$ \\
\hline$N$ & 1479 & 1430 & 1353 \\
\hline
\end{tabular}

Note. Models mirror those described in Table 4 in the body of the text. Huber-White robust standard errors in parentheses. Coefficients from logistic regressions presented as odds ratios. $\dagger p<0.1 ;{ }^{*} p<0.05 ;{ }^{\star \star} p<0.01$.

Cite this article: Doyle C, Swain WA, Swain Ewald HA, Ewald PW (2019). Inflammation, infection and depression: an evolutionary perspective. Evolutionary Human Sciences 1, e14, 1-19. https://doi.org/10.1017/ehs.2019.15 